\title{
DESÍGNIOS DA LEI DE TERRAS: imigração, escravismo e propriedade fundiária no Brasil Império
}

\author{
José Sacchetta Ramos Mendes*
}

\begin{abstract}
O artigo analisa as primeiras décadas do processo transição do regime escravocrata para o sistema de trabalho assalariado no Brasil (1840-1870). Dois fatores marcaram o período: a extinção do tráfico transatlântico de escravos e a necessidade cada vez maior de captar mão de obra para a cafeicultura brasileira. Entre as soluções que se buscaram para o impasse, destacaram-se as experiências que visavam a empregar trabalhadores livres estrangeiros, como os contratos de parceria e os de enganchado. Reclamações e revoltas de lavradores europeus contra os maus tratos nas fazendas de café resultaram em proibição da continuidade do agenciamento de trabalhadores para o Brasil. A promulgação da Lei Eusébio de Queirós, que pôs fim ao tráfico de escravos, deu-se duas semanas antes da promulgação da Lei de Terras, restritiva do acesso de pequenos agricultores à propriedade da terra. A obtenção de lotes passou a se dar por meio de compra e venda, não mais por posse e cessão, como ocorria desde os tempos coloniais. A medida dificultou o acesso à pequena propriedade rural e estimulou a expansão dos latifúndios em todo o país.

PALAVRAS-CHAVE: trabalho, legislação, imigração, revolta, café, Império do Brasil.
\end{abstract}

\section{INTRODUÇÃO: um modelo legal excludente de ocupação do território}

A primeira fase do processo de transição do regime escravocrata para o sistema de trabalho assalariado no Brasil, entre os anos de 1840 e 1870, conjugou a perspectiva final do tráfico de africanos à necessidade crescente de mão de obra para a cafeicultura. Em meio ao paradoxo, a implantação das diretrizes oficializadas pela Lei de Terras, de 1850, fez surgir um substrato jurídico de longa duração que marcaria a ocupação territorial do país. Encadeados, a crise do escravismo e o insucesso relativo das políticas de atração de trabalhadores livres europeus dominaram as relações de trabalho brasileiras na maior parte do século XIX, em proporção aos entraves que o legislador da época estabeleceu para obstaculizar o acesso de lavradores à propriedade da terra.

* Pós-doutorando em Filosofia e Teoria do Direito da Faculdade de Direito da USP. Doutor em História Social pela Universidade de São Paulo. Pesquisador do Laboratório de Estudos sobre Etnicidade, Discriminação e Racismo (LEER/USP). Pesquisador visitante no Centro de Estudos Brasileiros da Universidade de Columbia (Nova York). Largo São Francisco, 95. Cep: 01005-010. São Paulo - SP - Brasil.sacchett@usp.br
O deslocamento do eixo agroeconômico do Nordeste para o Centro-Sul, nas décadas seguintes à Independência, configurou pano de fundo para tentativas inovadoras de implantar o trabalho livre nos latifúndios, tendo em vista a expansão das culturas de café nas zonas agrícolas próximas ao Rio de Janeiro, a sede do Império.

Contratos de parceria com imigrantes europeus constituíram, então, o principal mecanismo utilizado para atrair lavradores estrangeiros em maior escala destinados às plantações de café, tomando impulso simultâneo à instalação do Segundo Reinado (1840-1889). Protagonista da introdução dos primeiros trabalhadores parceiros no Brasil, o fazendeiro e senador Nicolau Pereira de Campos Vergueiro integrava o grupo político de sustentação do chamado Golpe da Maioridade, que, em 1840, elevou ao trono precocemente o imperador Dom Pedro II.

Por iniciativa de Vergueiro, os acordos de parceria firmados entre latifundiários e agricultores tornaram-se frequentes na área cafeeira, no decênio anterior à promulgação da Lei de Terras e nos anos imediatos à sua edição. A experiência 
deu vislumbre a dificuldades práticas de fazer avançar a transição do escravismo para as relações capitalistas de trabalho.

Este artigo analisa o contexto em que se formaram as diretrizes fundiárias dominantes no Brasil durante a segunda metade do século XIX, a introdução dos contratos de parceria e as reclamações de maus tratos aos colonos estrangeiros nos cafezais. O foco está nos anos 1840 a 1870, momento em que fazendeiros da província de São Paulo estabeleceram o primeiro fluxo sistemático de imigração europeia para a cafeicultura. ${ }^{1} \mathrm{O}$ texto comenta a experiência da parceria agrícola iniciada pelo senador Nicolau Pereira de Campos Vergueiro, a revolta dos parceiros de língua alemã e as denúncias feitas por portugueses radicados no Rio de Janeiro, acerca dos abusos cometidos na lavoura contra seus conacionais. Ressalta, por fim, a edição da Lei de Terras, norteadora do desenho institucional de ocupação do território brasileiro, sugestivamente promulgada duas semanas após a Lei Eusébio de Queirós, que levaria à extinção do tráfico transatlântico de escravos.

\section{ESCRAVOS E HOMENS LIVRES: o trabalho nos cafezais}

Foi no bojo das transformações que a economia brasileira atravessou ao término das Regências (1831-1840) - com a substituição do açúcar pelo café como principal gerador de capitais - que se deu a primeira tentativa de parceria, destinada a promover a vinda sistemática de trabalhadores europeus para os cafezais de São Paulo. Empregavam-se, então, naquela cultura, contingentes ma-

1 A documentação que fundamenta este artigo constituise basicamente de correspondência diplomática do Brasil e de Portugal, sob guarda do Arquivo Histórico-Diplomático do Ministério dos Negócios Estrangeiros de Portugal (Lisboa) e do Arquivo Histórico do Itamaraty (Rio de Janeiro). A pesquisa foi feita no âmbito da tese de doutorado em História Social intitulada "Laços de Sangue. Privilégios e intolerância à imigração portuguesa no Brasil (1822-1945)", apresentada, em abril de 2007, no Departamento de História da Faculdade de Filosofia, Letras e Ciências Humanas da Universidade de São Paulo (FFLCH/USP), sob orientação de Maria Luiza Tucci Carneiro, com bolsa da Fundação de Amparo à Pesquisa do Estado de São Paulo (Fapesp) e do Instituto Camões. ciços de escravos de origem africana, em seguimento ao regime de produção predominante na cana-de-açúcar.

Em 1840, o senador Nicolau Pereira de Campos Vergueiro trouxe 90 lavradores da região do Minho, Norte de Portugal, para trabalhar como parceiros em sua Fazenda Ibicaba, próxima à cidade de Limeira, na província de São Paulo (Vergueiro [Carta], 1852). O contrato de parceria, firmado antes do embarque para o Brasil, estipulava que cada agricultor e sua família deveriam cultivar certa extensão de pés de café na fazenda que os acolhesse, recebendo em pagamento uma porcentagem do lucro líquido anual da venda do produto por eles gerado. A parceria empenhava daquele modo, por antecipação, o resultado do trabalho futuro do imigrante, com o qual ele deveria saldar os gastos feitos em seu benefício, desde a viagem marítima até os adiantamentos para compra de alimentos e subsistência.

O contrato previa também a possibilidade de transferência do parceiro a outros empregadores, independentemente da sua vontade, num negócio comercial que passou a ser comparado à revenda de escravos. Além dessas condições, nos latifúndios, o lavrador europeu passava a conviver lado a lado com negros cativos. Por vezes, eram empregados nas mesmas funções (Alencastro, 1988), estabelecendo-se um notável paralelo entre a parceria agrícola no café e a escravidão.

A fixação de imigrantes, nesse contexto, condicionava-se à necessidade imediata da grande lavoura, desvinculada de um projeto colonizador para o território. Na gênese da introdução do trabalho livre na cafeicultura, a mentalidade escravocrata do fazendeiro entendia que a organização dos núcleos populacionais, sobretudo na fronteira ocidental da zona cafeeira, deveria disponibilizar a mão de obra conforme os seus interesses. Afinal, era no interior dos vastos latifúndios que acontecia o povoamento efetivo da terra. Assinale-se que, nos anos anteriores à implementação do sistema de parceria no Brasil, o avanço das zonas agrícolas, em São Paulo e Minas Gerais, contou com um afluxo sem precedentes de escravos para aquelas províncias. 
A pressão internacional e os maiores riscos que corriam os traficantes provocavam, entretanto, sucessivos aumentos no preço dos africanos, deixando em alerta os cafeicultores, dependentes de uma mão de obra cujo suprimento iria em breve se exaurir (Costa, 1999). Sem que houvesse definição de políticas públicas de estímulo à imigração - prevendo ações específicas e designando verbas para executá-las - as tentativas oficiais de atrair lavradores europeus por meio de medidas legislativas não obtiveram sucesso. Leis destinadas a facilitar a naturalização, por exemplo, não surtiram o efeito desejado de promover a vinda espontânea de braços estrangeiros, delas fazendo uso, em sua maioria, portugueses radicados no meio urbano brasileiro, interessados em se habilitar, como cidadãos, a cargos no funcionalismo público.

Énesse panorama de escassa efetividade das ações governamentais em prol da imigração de trabalhadores livres para o café que se inseriu a iniciativa particular da parceria agrícola. Na origem, a adoção dos contratos de parceria por fazendeiros radicados em São Paulo visava a atrair lavradores da Europa Central: Suíça, França, Áustria-Hungria e, principalmente, as levas de imigrantes originários dos estados alemães que, desde a década de 1810, dirigiam-se em fluxo crescente para os Estados Unidos.

A maior disponibilidade no engajamento de portugueses para a lavoura brasileira fez, porém, com que Vergueiro optasse por abrir sua empreitada com os parceiros trazidos de Portugal. A experiência com agricultores do Minho foi seguida por contratos com pequenos grupos provindos das ilhas atlânticas: Açores e Madeira. O próprio senador era português da região de Trás-os-Montes, de onde havia emigrado para o Rio de Janeiro, e de lá para São Paulo, ainda no período de Reino Unido (1815-1821).

O desembarque dos primeiros parceiros para o café coincidiu com a decretação da maioridade de Dom Pedro II, ocorrida em 23 de julho de 1840, na esteira de um movimento liderado no Parlamento por políticos liberais como o senador Vergueiro. O Golpe da Maioridade levou para o trono do Brasil o jovem monarca de 14 anos de idade, à revelia da
Constituição do Império, de 1824, que, em seu artigo 121, dispunha que o príncipe era menor até os 18 anos completos e, como tal, não poderia ascender à Coroa. A vitória dos liberais monarquistas, pondo fim ao período regencial, vinculou-se, assim, à busca por hegemonia, na Corte, do polo latifundiário cafeicultor, em marcha para o Oeste da província de São Paulo.

O triunfo liberal concretizado naquela jogada parlamentar teve, entretanto, efeito limitado. Dois anos depois, em 1842, a situação política se inverteu e os liberais de São Paulo e Minas Gerais foram derrotados pelas forças conservadoras, que reassumiram a dianteira na condução do Estado imperial. O transtorno impediu por certo tempo a vinda de novos grupos de parceiros, tarefa retomada pelo senador Vergueiro quando inaugurou, em 1846, a sua Casa Vergueiro \& Cia., firma comercial que, entre outras funções, realizava o engajamento de imigrantes na Europa para trabalhar na cultura do café, no Brasil.

Em julho de 1847, Vergueiro deu novo impulso aos contratos de parceria, ao promover a vinda de 423 agricultores alemães para a sua Fazenda Ibicaba, a mesma onde, desde 1840, trabalhava o grupo inaugural de parceiros portugueses. A retomada da experiência tornou-se ponto de partida para a adoção da parceria em maior escala com trabalhadores livres europeus, na zona cafeeira paulista. Foram trazidos suíços de língua alemã e francesa, belgas, alemães de várias regiões, portugueses das ilhas e do continente, além de trabalhadores livres brasileiros. Os contratos de parceria difundiram-se rapidamente. Entre 1847 e 1857, eram praticados em mais de 60 grandes fazendas de café do Oeste Paulista, cada uma delas a empregar, em média, de 700 a 1000 lavradores parceiros, quase todos imigrantes (Holanda, 1980).

\section{"ESCRAVIDÃO BRANCA"}

Apesar da precedência dos portugueses como os primeiros parceiros na cafeicultura paulista, os imigrantes de língua alemã foram os 
mais notabilizados naquele sistema trabalho. Isso se deu por terem sido relativamente significativos, em termos numéricos, no regime de parceria. Mas é plausível supor que a notoriedade da presença alemã nas fazendas de café, nos anos 1840-1850, deveu-se à publicidade negativa que as críticas ao tratamento a que eram submetidos obteve nos países de origem. Em meados do século XIX, o café se tornava uma bebida conhecida na Europa Central, propiciando algum destaque às zonas produtoras, sobretudo quando se tratava de um destino imigratório, como era o caso de São Paulo.

Uma rebelião de parceiros de língua alemã, ocorrida na Fazenda Ibicaba, em 1857, liderada pelo suíço Thomas Davatz, mobilizou a diplomacia helvética no Rio de Janeiro e repercutiu nas regiões centro-europeias onde mais se buscava engajar trabalhadores para a grande lavoura, com o aumento da propaganda contrária à imigração para o Brasil. Reclamações e revoltas de menor proporção ocorreram noutras fazendas de café paulistas, invariavelmente agitadas por lavradores alemães.

Em reação às denúncias, o governo da Prússia suspendeu a autorização de trabalho dos agentes que captavam imigrantes em suas aldeias. O rescrito de Heidt, decreto promulgado em Berlim, em 1859, proibiu o agenciamento de colonos agrícolas prussianos para a província de São Paulo. O veto depois se estendeu para o Sul do Brasil, muito além da própria zona cafeeira. Medidas restritivas no mesmo sentido foram tomadas por outros estados alemães e pela França. E, nos cantões suíços de língua alemã, passaram a correr notícias da prática de "escravidão branca” na cafeicultura brasileira (Levy, 1974).

Thomas Davatz, ao retornar à Suíça, após a revolta na Fazenda Ibicaba, escreveu suas memórias acerca do tempo em que trabalhou como colono lavrador nas plantações de café de São Paulo, sob o sistema de parceria. Nessas anotações, impressas em livro em 1858, narrou as dificuldades que vivenciara, como no trecho a seguir:

Os colonos que emigram, recebendo dinheiro adiantado, tornam-se, pois, desde o começo, uma simples propriedade da Vergueiro \& Cia. E em virtude do espírito de ganância [...] que anima numerosos senhores de escravos, e também da ausência de direitos em que costumam viver esses colonos na província de São Paulo, só lhes resta conformarem-se com a ideia de que são tratados como simples mercadorias, ou como escravos (Davatz, 1980).

As palavras de Davatz expressam a percepção e o ponto de vista de um imigrante que se empregou na cultura do café, ainda em meados do século XIX, como fizeram milhares de homens de diversas nacionalidades. Seu relato, simples e direto, permanece um testemunho sobre o regime de parceria, mais uma vez aproximando-o do escravismo-não importa aqui a imprecisa relação conceitual traçada pelo lavrador suíço entre o parceiro e o escravo.

Adotada nos Estados Unidos no século XVIII, a parceria agrícola logo caiu em desuso naquele país, tendo em vista a enorme extensão de terras da América do Norte disponíveis para assentamento de lavradores, num quadro de liberalidade jurídica no acesso à pequena propriedade, tanto por norte-americanos quanto por estrangeiros. No Brasil, por sua vez, o contrato de parceria entrou em decadência após a revolta de 1857 na Fazenda Ibicaba, episódio que fez cessar por vários meses a vinda de novos imigrantes da Europa Central para a província de São Paulo (Witter, 1987). O regime de trabalho adotado por mais de uma década para fixar braços livres na cafeicultura desmantelou-se rapidamente.

Na Bahia e em Pernambuco, ainda ocorreram, sem sucesso, tentativas posteriores de implantar formas de parceria na cultura do açúcar. Há notícias de que, em 1858-1859, o senhor de engenho Tomás Pedreira Geromoabo trouxe 105 trabalhadores portugueses para a Fazenda Engenho Novo, no Recôncavo Baiano (Lyra, 1982 apud Mattoso, 2000). Um ano depois, a maioria teria deixado as plantações e se transferido para as vilas da região.

Na província de São Paulo, os acertos contratuais com os parceiros para o café foram afrouxados, como a cláusula que obrigava o grupo a responder solidariamente pelas dívidas de cada um com o fazendeiro. A maioria dos proprietários de 
terras abandonou a parceria, passando alguns a pagar salário fixo ao trabalhador livre, fosse ele brasileiro ou estrangeiro. Na Fazenda Ibicaba, Vergueiro e seus descendentes adotaram variantes de contratos de locação de serviços (Holanda, 1980).

\section{OS MAUS TRATOS AOS PORTUGUESES}

A força das denúncias dos ex-parceiros alemães e suíços e das revoltas por eles protagonizadas no interior de São Paulo deve ser levada em conta quando se avaliam as razões para a falência do sistema de parceria. Medidas restritivas tomadas por governos estrangeiros, ainda na década de 1850, ganham relevância histórica, como primeira reação oficial efetiva contra a imigração para o Brasil. Nesse aspecto, vale ressaltar que, antes mesmo da rebelião que expôs, na Europa Central, as condições de trabalho dos lavradores de língua alemã, a situação penosa enfrentada pelos europeus nas fazendas brasileiras já era conhecida das autoridades de Portugal, país que estivera como um dos polos de captação de parceiros para a cafeicultura.

Reclamações de maus tratos a portugueses e denúncias de aliciamento enganoso para as zonas agrícolas e as grandes plantações vinham sendo veiculadas na imprensa lusitana e registradas por políticos desde a década de 1830, previamente, portanto, aos primeiros contratos de parceria. ${ }^{2}$ Não consta ter havido, porém, movimento que, partindo dos trabalhadores lusos ou os abrangendo, a exemplo da rebelião dos parceiros de língua alemã, se voltasse contra as alegadas más condições a que estariam submetidos.

No período em que predominaram os contratos de parceria, as denúncias chegaram a ser

2 A presença de lavradores açorianos e madeirenses na cafeicultura remonta ao final da década de 1820 . É de 13.01.1838 o célebre artigo publicado por Alexandre Herculano no Diário do Governo de Lisboa, no qual o autor reclama às autoridades de Portugal maior atenção para o fenômeno imigratório, que envolvia naqueles dias um número crescente de portugueses em direção às áreas agrícolas brasileiras, e cuja realidade, segundo suas palavras, mostrava-se tristemente espantosa. Para uma discussão sobre a abordagem da imigração para o Brasil por parlamentares e intelectuais portugueses na primeira metade do século XIX, ver Maia (2002). articuladas por imigrantes portugueses estabelecidos no meio urbano brasileiro, em oposição ao engajamento de mão de obra para a cafeicultura. Numa dessas manifestações, ocorrida em janeiro de 1852, uma petição assinada por um grupo de moradores lusitanos do Rio de Janeiro solicitava providências ao diplomata José de Vasconcellos e Sousa, ministro plenipotenciário de Portugal no Brasil:

Os abaixo-assinados, súditos portugueses e negociantes estabelecidos nesta praça do Rio de Janeiro, não podem por mais tempo ser indiferentes ao triste e aviltante espetáculo que se oferece a seus olhos, sempre que no porto da capital do Império aporta algum navio procedente das ilhas portuguesas. É triste [...] é doloroso o quadro que então se desdobra à vista de todos [...]

Especuladores ambiciosos [têm] arrebatado para aqui, a título de colonos, indivíduos de ambos os sexos das ilhas portuguesas, e principalmente dos Açores, pondo em prática os meios mais torpes e asquerosos, como sejam a mentira, a sedução, a infâmia e até o roubo. Então esses moços inexperientes, que julgam encontrar um novo El Dorado, essas jovens donzelas, fascinadas por mágicas grandezas, essa pobre gente enfim conduzida por tais meios para o Brasil, tarde conhecem o engano, e suas esperanças convertemse em torturas do inferno.

Esses especuladores, verdadeiras feras [...] estabelecem a arbítrio o preço da passagem, e então são os passageiros condenados a um cativeiro sem remédio, são comprados pelo dinheiro. [...] Um tráfico vergonhoso e degradante esse que, na realidade, se efetua aos olhos de todos, e que, para opróbrio da humanidade, se repete frequentemente, e com um abuso inqualificável (D’Amorim [Petição], 1852). ${ }^{3}$

O trecho descreve a situação de jovens portugueses ao desembarcarem no país, sob a ótica de imigrantes fixados na capital do Império: os que chegavam, atraídos "a título de colonos" para a lavoura, estariam, conforme o relato, "condenados" ao "cativeiro", após terem sido "comprados pelo dinheiro" (D’Amorim [Petição], 1852). Não difere substancialmente das queixas dos lavradores suíços e alemães contratados como parceiros pelos fazendeiros de café. A documentação da época é rica em acusações de abuso a imigrantes no Brasil. O que torna inusitada a petição é o fato de negoci-

${ }^{3}$ Foram localizadas em arquivo as três primeiras páginas do abaixo-assinado, em que constam o texto-abertura, 15 nomes de portugueses e indicação provável de um número maior de assinaturas (D’Amorim [Petição], 1852). 
antes lusos estabelecidos na Corte tomarem a palavra em defesa de gente das ilhas atlânticas lusitanas que estaria a ser enganada por especuladores.

Seu apelo é contra a "indiferença”, pois já não suportam o "triste e aviltante espetáculo que oferece aos seus olhos", ainda de acordo com a petição de 1852 firmada pelo grupo de portugueses do Rio de Janeiro. O drama teria sido frequente no então principal cais de desembarque de estrangeiros no país - o porto de Santos só tomaria a dianteira no recebimento de imigrantes nos anos 1870.

Uma discrepância que se observa na leitura da documentação consular e de imprensa lusitana do período, comparada à atitude de outros países emissores de imigrantes, era a dificuldade da diplomacia de Portugal responder a denúncias de maus tratos contra seus nacionais (Maia, 2002), diante do volume proporcionalmente maior de portugueses que faziam do Brasil seu destino. A postura da legação lusa no Rio de Janeiro foi por diversas vezes considerada de alheamento. Nos jornais de Lisboa e do Porto, as críticas que envolviam a situação dos trabalhadores na cafeicultura atacavam a suposta benevolência dos diplomatas daquele país para com os interesses do Império.

No aniversário de 35 anos da Independência do Brasil, em setembro de 1857, concomitante à revolta dos parceiros de língua alemã na Fazenda Ibicaba, o lisboeta Jornal do Commercio publicou, em editorial de primeira página, um texto atacando o que denominou "ignominiosa fraqueza" da representação consular de Portugal na ex-colônia, frente aos abusos dos imigrantes arregimentados para trabalhar no café, e diante dos "procedimentos arbitrários das autoridades brasileiras contra súditos portugueses". (Editorial [Jornal do Commercio], 1857).

A legação diplomática de Portugal, da sua parte, admirava-se com o "estado próspero" da economia brasileira e chamava a atenção para os recursos crescentes com que contava o Império. A criação do terceiro Banco do Brasil, tendo por objetivo substituir por metal o papel fiduciário em circulação, foi compreendida como exemplo da afluência de capitais. José de Vasconcellos e Sousa, principal representante de Lisboa no Rio de Janei- ro, explicitava, em carta, sua expectativa de que ao "maior desenvolvimento não venha opor-se à falta de braços" (Sousa [Ofício n. 20], 1853). Sobre as reclamações de maus tratos a lavradores imigrantes, entretanto, o diplomata relativizava: "não me consta a existência de um só [estabelecimento rural no Brasil] onde não se queixem ou os colonos ou os proprietários das terras, sendo que pela maior parte, segundo ouço, vivem descontentes uns e outros!" (1853).

\section{CONTORNOS DA LEI DE TERRAS}

As condições dos trabalhadores livres na cultura do café em meados do século XIX, ponto de inflexão do escravagismo no Brasil, estiveram amplamente relacionadas à estreita mobilidade social a eles relegada pela ordem jurídica do Segundo Reinado. Foi nesse sentido que se concebeu a principal legislação do período sobre ocupação do território, a Lei de Terras (Lei n. 601, de 18.09.1850), geradora de efeitos de longa duração para a propriedade fundiária e o povoamento do país. A medida transformou as áreas devolutas em mercadoria comercializável pelo Estado. A obtenção de lotes agrícolas passava a se dar exclusivamente por meio de compra e venda, não mais por cessão gratuita em nome do sesmeiro ou do posseiro, como ocorria desde o tempo colonial.

Já no artigo $1^{\circ}$, a Lei n. 601/1850 determinava: "ficam proibidas as aquisições de terras devolutas por outro título que não seja o de compra”. No artigo $3^{\circ}$, inciso IV, definia: "são terras devolutas: [...] as que não se acharem ocupadas por posse que, apesar de não se fundarem em título legal, foram legitimadas por esta lei”.

Consequência do dispositivo foi impedir a maioria dos lavradores de ter acesso à propriedade da terra. E como os que imigravam para o Brasil eram geralmente europeus empobrecidos e sem recursos, não tinham como adquirir um lote de maneira legal, tornando-se propensos a fornecer sua força de trabalho para a grande lavoura, até que acumulassem meios necessários à compra de 
um terreno agriculturável (Beiguelman, 2005). A nova legislação de terras sintetizava a diretriz restritiva, definidora do papel social do imigrante como mão-de-obra agrícola a se empregar nos latifúndios. Em paralelo à opção de continuísmo da escravidão, a permanente necessidade de novos suprimentos de braços para a cafeicultura levou à caracterização do trabalhador estrangeiro que se desejava atrair.

O modelo consolidado pela Lei de Terras constituiu obstáculo jurídico central ao desenvolvimento da pequena propriedade agrícola no Brasil, durante o século XIX, tornando-se um empecilho histórico à democratização do solo, com decorrências futuras para o país (Rebouças, 1870 apud Taunay, 1924). Seus contornos formais vinham sendo delineados pela elite cafeicultora do Centro-Sul há mais de duas décadas, ou seja, desde o final do Primeiro Reinado (1822-1831), como uma saída para a anunciada crise do escravismo. Sua promulgação, ocorrida no curso da experiência dos contratos de parceria, quando o fluxo imigrantista de trabalhadores livres para a cafeicultura momentaneamente se fortaleceu, parecia confirmar o desígnio que estivera na base de sua concepção.

A Lei de Terras consubstanciou em norma jurídica a proposta debatida na Seção do Império do Conselho de Estado, ainda em 1842, por encaminhamento do então senador e ex-ministro da Justiça Bernardo Pereira de Vasconcelos, que visava a impedir a compra de terrenos agrícolas por imigrantes adventícios, para forçar os que chegavam a se empregar na lavoura cafeeira. O parecer do Conselho de Estado, emitido em 08.08.1842, acatou a ideia de dificultar o acesso à propriedade agrícola, propondo colocar um fim à doação de terras para trabalhadores livres estrangeiros:

Um dos benefícios da providência que a Seção [do Império] tem a honra de propor a V. M. Imperial é tornar mais custosa a aquisição de terra [... Como a profusão de datas de terras tem, mais que outras causas, contribuído para a dificuldade que hoje se sente de obter trabalhadores livres, é seu parecer que de ora em diante sejam as terras vendidas sem exceção alguma. Aumentando-se, assim, o valor das terras e dificultandose, consequentemente, a sua aquisição, é de es- perar que o imigrado pobre alugue o seu trabalho efetivamente por algum tempo, antes de obter meios de se fazer proprietário (Parecer [Conselho de Estado], 1842).

Oito anos depois, ao ser sancionada, a Lei de Terras transformou em norma legal o objetivo daquele parecer. Possibilitou, com isso, a regulamentação de algumas pendências da política de estrangeiros que vinham sendo proteladas, como o decreto n. 291, de 30.08.1843, que facultava a naturalização do imigrante após dois anos de residência no Brasil e garantia dispensa do serviço militar aos novos cidadãos. A lei criou também a Repartição de Terras Públicas, encarregada de dirigir a medição, divisão e descrição das terras devolutas e sua conservação, de fiscalizar a venda e distribuição e de promover a colonização do território. O órgão passou a se organizar nas províncias e deveria impulsionar ações locais em assuntos de imigração. Seu âmbito de competência fundava-se na Lei n. 514, de 28.10.1848, que ampliou a abrangência da esfera provincial naqueles temas. Apesar das terras devolutas permanecerem centralizadas no Império, retomava-se o esforço público para atrair imigrantes.

O decreto n. 1.318, que regulamentou em detalhes a Lei de Terras, foi sancionado em 30.01.1854, garantindo eficácia jurídica ao sistema fundiário imposto pelos cafeicultores. A tarefa foi corroborada pela edição de portarias imperiais, leis provinciais e diretivas locais. A maneira pela qual se fez a ocupação de extensas áreas das províncias de São Paulo, Rio de Janeiro e Minas Gerais, a partir dos anos 1850, foi decorrência direta daquela legislação. Sua importância pode ser dimensionada na vasta proporção das zonas devolutas que compunham o território brasileiro e cujo acesso se tratou de dificultar.

Entretanto, a interpretação flexível do artigo $3^{\circ}$, inciso IV, da Lei de Terras (que admitia e legitimava a posse concretizada antes da promulgação da lei), confirmada no Regulamento de 1854, ensejou a aquisição fraudulenta de terrenos públicos mediante legitimação, por oficio, de posse alegadamente anterior. A prática se generalizou, 
resultando na ocorrência sistemática de falsas posses em todo o país, na segunda metade do século XIX, até o período republicano. As fraudes na obtenção de escrituras raramente eram cometidas por lavradores, eles próprios vítimas de posseiros e empresas colonizadoras que lhes revendiam os terrenos. Na maioria das vezes, os beneficiados foram grandes proprietários e não agricultores sem terra, fossem eles brasileiros ou imigrantes (Lopes, 2002).

Nas áreas cafeicultoras, o destino da maioria das terras roxas devolutas incorporadas ao domínio particular favoreceu a persistência do sistema de latifúndio, em detrimento da pequena propriedade. Nas áreas férteis do Oeste Paulista, entre as décadas de 1850 e 1890, o avanço de posseiros e matadores de índios, os bugreiros, sobre territórios habitados por indígenas kaingangs, guaranis e terenas deixou como marca as expulsões, o morticínio e o desmantelamento de suas sociedades (Monbeig, 1998). Do ponto de vista legal, tais ações não encontravam amparo, mas suas consequências foram legitimadas pela brecha oferecida à apropriação de terra que se demonstrasse ter ocorrido antes de 1854, a depender da interpretação da lei ou da generosidade de seu agente.

Mesmo na província do Rio Grande do Sul, distante das plantações de café, estimados 750 mil hectares de terras devolutas teriam sido transferidos de modo fraudulento a particulares, por meio de falsas legitimações, nos 35 anos que separaram o Regulamento da Lei de Terras e a Proclamação da República (Roche, 1969). Essa situação também se verificou em grande escala no Paraná, em Santa Catarina e no Espírito Santo.

\section{OBSTÁCULO À PEQUENA PROPRIEDADE FAMILIAR}

Foram escassos os resultados da Lei de Terras e de seu Regulamento, em prol dos objetivos imigrantistas dos cafeicultores brasileiros: a "substituição dos pretos escravos por gente branca que se dedique à lavoura e cultura de suas terras”, nas palavras da diplomacia portuguesa no Brasil, atenta

à questão (Sousa [Ofício n. 17], 1854). Com efeito, os anos 1850, imediatamente seguintes à extinção do tráfico transoceânico de escravos, viram estancar o suprimento de braços da África para a cafeicultura do Brasil, ao mesmo tempo em que não se concretizou "a colonização europeia, na qual se fala sempre, é verdade, mas que de fato está ainda mui longe" (Sousa [Ofício n. 20], 1853).

Na sessão de abertura do Parlamento do Império, em maio de 1855, Dom Pedro II declarou, num arroubo inusitado, que o futuro do Brasil dependia "essencialmente da colonização estrangeira”, tarefa para a qual seu governo deveria ter "particular solicitude [e] empenho" (Dom Pedro II [Fala do Trono], 1855). Três anos depois, na Fala do Trono com que abriu a legislatura anual do Parlamento, o imperador reconheceu que "a colonização tem sofrido tropeços” (1858). Afirmou também a necessidade de haver cumprimento fiel dos contratos firmados na Europa, para garantir a "sorte futura dos imigrantes" e desfazer

\begin{abstract}
... preocupações pouco favoráveis à vinda de colonos para o Império. Para se conseguir este benefício tão insistentemente reclamado pelas circunstâncias de nossa produção agrícola, faz-se necessária uma lei que inspire ao emigrante inteira confiança na pátria de sua adoção (Dom Pedro II, [Fala do Trono], 1858).
\end{abstract}

As rebeliões de lavradores estrangeiros ocorridas em fazendas de café da província de São Paulo - especialmente a revolta em 1857 dos colonos parceiros suíços e alemães - e o quadro normativo consolidado pela Lei de Terras e seu Regulamento instauravam uma situação pouco favorável à vinda de imigrantes agricultores. A lei preconizada por Dom Pedro II na Fala do Trono de 1858 não foi instituída, ao passo que a legislação já em vigor não poderia “inspirar" nos trabalhadores europeus, os quais o imperador desejava atrair, a confiança na futura "pátria de sua adoção”, conforme seus termos.

Em sentido diverso, relatos da época davam conta de que, nos principais portos de partida da Europa, ampliavam-se os embarques para os Estados Unidos, cuja política de povoamento facilitava o acesso à propriedade da terra pelos re- 
cém-chegados, além de combater as relações de servidão no trato com estrangeiros (Costa, 1999). A promulgação do Homestead Act pelo governo federal de Washington, em 1862, instituiu a cessão de pequenas glebas de terra devoluta a quem nelas desejasse se instalar. Nos vinte anos seguintes, cerca de sete milhões de europeus se radicaram naquele país, a maioria nas novas zonas de assentamento agrícola do Meio-Oeste. ${ }^{4}$

$\mathrm{Na}$ conjuntura brasileira, o movimento imigratório vivenciou na Lei de Terras uma guinada, a partir do que as cidades, em particular o Rio de Janeiro, ganharam nova importância como lugar de fixação de estrangeiros. O obstáculo imposto à aquisição de um lote para cultivar fez com que parte dos que aportavam de forma espontânea no Brasil desistissem de se dirigir para a agricultura e se voltassem, logo após o desembarque, para atividades urbanas, inversamente do que pretendeu o legislador.

Sublinhe-se quea Lei de Terras, de 18.09.1850, foi editada duas semanas após a Lei Eusébio de Queirós, de 04.09.1850, que fez cessar a importação de escravos da África. O fim do tráfico instaurou a crise definitiva no fornecimento de mão de obra para a lavoura, ao gerar uma ruptura que há muito se previa, mas que pouco se fizera para minorar consequências.

Alternativa imediata foi adquirir cativos em regiões de economia decadente do Nordeste e deslocá-los para o Centro-Sul, num movimento de dimensão controversa e resultados pouco lucrativos. Em todo caso, verificavam-se novos esforços por canalizar braços trabalhadores para as plantações de café. A imigração para o Brasil adentrava, assim, a perspectiva aberta com o fim do tráfico transatlântico de escravos, que liberou capitais depois aplicados noutras atividades, inclusive no financiamento da vinda de imigrantes. Por um tempo, o comércio interprovincial de escravos teria se

\footnotetext{
${ }^{4}$ O fim legal da escravidão nos Estados Unidos, em 1865, determinou novo impulso à imigração naquele país. Segundo dados do United States Bureau of Census, entre os anos 1841-1880, entraram naquele país 9,4 milhões de imigrantes. Para análise comparativa da política de terras do Brasil e EUA, ver Costa (1999, p.169-193).
}

beneficiado desses recursos. Mas a transformação da fazenda de café em unidade empresarial capitalista fazia do escravo um item mais custoso que o imigrante (Costa, 1999). O emprego da mão de obra remunerada, por sua vez, barateava e racionalizava a manutenção da força de trabalho.

A partir do Rio de Janeiro, diplomatas europeus ressaltavam a vantagem econômica do trabalhador livre empregado nas plantações: "Cada negro escravo custa hoje uma soma entre um conto e quinhentos réis e dois contos de réis. E quanto custa ao Brasil um colono português, dos quais uma boa parte se ocupa na agricultura, substituindo o trabalho dos negros? Custa o preço da passagem, ou R\$120\$000 [120 mil réis]”, assinalou o Conde de Tomar (1859), encarregado de negócios de Portugal na capital brasileira, em carta endereçada a sua chancelaria em Lisboa.

Nova tentativa de atrair lavradores europeus para as fazendas de café em caráter sistemático só tomou impulso em 1871, quando a província de São Paulo estabeleceu políticas próprias para captação de imigrantes na Itália e Áustria-Hungria, com financiamento privado e estatal do transporte direto de colonos para o porto de Santos, e dali para o interior paulista. Na década anterior, o que se verificou foi um fluxo de pequeno vulto, ainda que contínuo, de portugueses e outros estrangeiros encaminhados para os cafezais - a correspondência diplomática da época continuou a trazer informações sobre o engajamento de açorianos e madeirenses (Conde de Tomar [Ofício Reservado n. 13], 1859) para "substituir o trabalho escravo no café” (Sousa [Ofício n. 64], 1858). Até a vinda de lavradores italianos em maior número, a partir de 1873, os lusos configuraram o rosto do trabalhador livre imigrante que predominou no país.

Tanto assim que, em 1866, o jurista Agostinho Marques Perdigão Malheiro observou que a imigração alemã, "que pareceu algum tempo buscar de preferência o Império, desviou-se para o Norte" (Malheiro, 1866) e se encaminhou para os Estados Unidos, como também o fizeram os fluxos de todas as nacionalidades, à exceção da portuguesa: 
Só nos restou mais constante a [corrente imigratória] dos portugueses e ilhéus, seguramente pela comunidade de raça, de língua, de religião, origem, costumes e relações. Mas esta prefere o comércio e outras indústrias, a vida nas cidades e povoados; e conquanto não seja para desprezar, e ao contrário também nos serão úteis, todavia, a lavoura não recebe o principal reforço de que precisa, e que convém promover (Malheiro, 1866).

\section{CONSIDERAÇÕES FINAIS}

A edição da Lei Eusébio de Queirós e da Lei de Terras, em agosto de 1850, projetou um modelo de longa duração na ocupação territorial brasileira, com decorrências notáveis na composição fundiária do país. Tratava-se de um desígnio consciente de exclusão debatido às claras, como se viu, no Parlamento do Império. Com o fim do tráfico de africanos, a crise do escravismo entrou na fase aguda, em que a reprodução do sistema passaria a ser paulatinamente atingida pelo avanço da legislação abolicionista. No contexto, as experiências "inovadoras" de contratos de trabalho (parceria, enganchamento) com agricultores europeus iluminaram uma perspectiva em que o acesso à propriedade da terra tornava-se algo distante, fator que contrapunha desfavoravelmente o Brasil aos Estados Unidos, como destino imigratório em larga escala.

A Lei Eusébio de Queirós, tomada como marco político, expande sua nota conjuntural, se observada com a Lei de Terras e o seu Regulamento. A análise dos dispositivos destaca a contemporaneidade existente entre o instituto que extinguiu o tráfico de escravos, a lei que restringiu a aquisição legítima da propriedade agrícola e a caracterização do trabalhador imigrante desejado pelo legislador no Segundo Império.

O aspecto excludente da Lei de Terras, oficializado naquela fase inicial do processo de Abolição da Escravatura, indicava a dominância oligárquica na condução da política imperial. Sua abrangência se fez sentir em todo o país, diante da continuidade do escravismo por mais quatro décadas. No período, a questão fundiária manteve- se sob os parâmetros restritivos do parecer de 1842 do Conselho de Estado. Combinadas com o limite legal imposto, as experiências de contrato de trabalho entre latifundiários e homens livres, brasileiros ou estrangeiros, deram mostras do impedimento à ocupação do território por pequenos lavradores sem terra. Ao mesmo tempo, expressaram o dramático vislumbre do fim da escravidão e a prolongada busca por um novo estatuto para o trabalho no Brasil.

(Recebido para publicação em abril de 2008) (Aceito em fevereiro de 2009)

\section{REFERÊNCIAS}

ALENCASTRO, Luiz Felipe de. Escravos e proletários. Novos Estudos CEBRAP, São Paulo, n. 21, p. 30-56, jul., 1988.

BEIGUELMAN, Paula. A formação do povo no complexo cafeeiro. 3.ed. São Paulo: EDUSP, 2005.

COSTA, E. Viotti da. Da monarquia à república. 7.ed. São Paulo: Ed. UNESP, 1999.

CRUZ, Maria Antonieta. Agruras dos emigrantes portugueses no Brasil. Revista de História. Porto, Pt , Universidade do Porto, v. 7, p. 129-31, 1986/1987.

DAVATZ, Thomas. Memórias de um colono no Brasil (1850). Belo Horizonte: Itatiaia; São Paulo: Edusp, 1980

HOLANDA, Sergio Buarque. Prefácio do tradutor. In DAVATZ, Thomas. Memórias de um colono no Brasil (1850). Belo Horizonte: Itatiaia; São Paulo: Edusp, 1980. p. $15-45$.

KLEIN, Herbert. A integração social e econômica dos imigrantes portugueses no Brasil nos finais do século XIX e no século XX. Revista Brasileira de Estudos de População. São Paulo, ANPOCS, n.2, v.6, p.17-37, 1989.

LEVY, Maria Stella Ferreira. O papel da imigração internacional na evolução da população brasileira (1872 a 1972). Revista de Saúde Pública, São Paulo, Faculdade de Saúde Pública da USP, n. 8, Supl., p.49-90, 1974.

LOPES, José Reinaldo de Lima. O direito na história. 2.ed. São Paulo: Max Limonad, 2002.

MALHEIRO, Agostinho Marques Perdigão. A escravidão no Brasil, ensaio historico-juridico-social. Rio de Janeiro: Typographia Nacional, 1866.

MAIA, Fernanda Paula Sousa. O discurso parlamentar português e as relações Portugal-Brasil: Lisboa: Fundação Calouste Gulbenkian, 2002.

MATTOSO, Kátia. Sociedade escravista e mercado de trabalho: Salvador, 1850/1868. Bahia: Análise \& Dados. Salvador, SEI, v.10 n.1, p. 12-20, 2000

Sociedade escravista e a Câmara dos Deputados 1826/1852). Mercado de trabalho: Salvador, 1850/1868. Bahia: Análise \& Dados, Salvador, SEI, v. 10 n. 1, 2000.

MENDES, José Sacchetta Ramos. Laços de Sangue. Privilégios e intolerância à imigração portuguesa no Brasil 
(1822-1945). 2007. Tese (Doutorado em História Social) Departamento de História da Faculdade de Filosofia, Letras e Ciências Humanas da Universidade de São Paulo. 2007.

MONBEIG, Pierre. Plantadores e fazendeiros de São Paulo. 12.ed. São Paulo: Hucitec, 1998.

ROCHE, Jean. A colonização alemã e o Rio Grande do Sul. Porto Alegre: Globo, 1969.

TAUNAY, Alfredo de Escragnolle (Visconde de). Homens e cousas do Império. 2.ed. São Paulo: Weiszflog, 1924.

WITTER, J. S. A revolta dos parceiros, o choque da imigração. São Paulo: Brasiliense, 1987.

\section{Documentos de Arquivo}

CARTA de Nicolau Pereira de Campos Vergueiro a José Tomás Nabuco de Araújo, presidente da província de São Paulo; Fazenda Ibicaba/SP, 06.01.1852. In: LATA COLÔNIAS AGRÍCOLAS, no 7.212 , 1855/1867, Arquivo do Estado de São Paulo, transcrita por SILVA, Maria Beatriz Nizza da. Documentos para a história da imigração portuguesa no Brasil (1850/1938). Rio de Janeiro: Federação das Associações Portuguesas e Luso-Brasileiras, 1992, p. 34-35.

EDITORIAL “Lisboa, 7 de Setembro”. Jornal do Commercio, Lisboa, 08.09.1857, p.1; Legação de Portuga no Rio de Janeiro (LPRJ), correspondência recebida, 1854/ 1855, caixa 203, maço 5, Arquivo Histórico-Diplomático do Ministério dos Negócios Estrangeiros de Portugal (AHDMNE).

FALA do Trono de Dom Pedro II na abertura da $2^{\mathrm{a}}$ sessão da $9^{a}$ legislatura da Assembleia Geral Legislativa (AGL), 03.05.1855; anexo ao ofício $\mathrm{n}^{\mathrm{O}} 13$ de João Gomes de Oliveira Silva Bandeira de Mello, encarregado de negócios de Portugal no Brasil, a António Aloísio Jervis de Atouguia, ministro dos Negócios Estrangeiros de Portugal; Rio de Janeiro [1855]; LPRJ, correspondência recebida, 1854/1855, caixa 203, maço 3, AHD-MNE.

FALA do Trono de Dom Pedro II na abertura da $2^{\mathrm{a}}$ sessão da $10^{a}$ legislatura da AGL, 03.05.1858; anexo ao ofício n. ${ }^{\circ}$ 31 de José de Vasconcellos e Sousa, encarregado de Negó- cios de Portugal no Brasil, a António Aloísio Jervis de Atouguia; Rio de Janeiro, 14.05.1858; LPRJ, correspondência recebida, 1858/1859, caixa 204, maço 1, AHD-MNE.

LIBELO acusatório contra o diplomata português João Baptista Moreira, anexo ao ofício n. ${ }^{\circ} 10$ da LPRJ a António Aloísio Jervis de Atouguia; Rio de Janeiro [1854]; LPRJ, correspondência recebida, 1854/1855, caixa 203, maço 2 , AHD-MNE.

OFICIO n.20 de José de Vasconcellos e Sousa a António Aloísio Jervis de Atouguia; Rio de Janeiro, 11.05.1853, LPRJ, correspondência recebida, 1853, caixa 202, maço 5, AHD-MNE.

OFÍCIO n.17 de José de Vasconcellos e Sousa a António Aloísio Jervis de Atouguia; Rio de Janeiro, 13.03.1854; maço 2, AHD-MNE.

OFÍCIO n.64 de José de Vasconcellos e Sousa a Nuno Severo de Mendonça e Moura (Marquês de Loulé), ministro dos Negócios Estrangeiros de Portugal; Rio de Janeiro, 04.10.1858; LPRJ, correspondência recebida, 1858/1859, caixa 204, maço 1 , AHD-MNE.

OFÍCIO reservado n.4 do Conde de Tomar, encarregado de negócios de Portugal no Brasil, a António José de Sousa Severin de Noronha (Duque da Terceira), ministro dos Negócios Estrangeiros de Portugal; Rio de Janeiro, 11.11.1859; LPRJ; correspondência recebida, 1858/1859, caixa 204, maço 2, AHD-MNE.

OFÍCIO reservado n.13 do Conde de Tomar ao Duque da Terceira; Rio de Janeiro, 08.12.1859; LPRJ; correspondência recebida, 1858/1859, caixa 204, maço 2, AHD-MNE.

PARECER da Seção do Império do Conselho de Estado à consulta de Bernardo Pereira de Vasconcelos e José Cesário de Miranda Ribeiro; Rio de Janeiro, 08.08.1842. Imperiais resoluções tomadas sobre consultas da seção de Justiça do Conselho de Estado: desde o ano de 1842, em que começou a funcionar o mesmo Conselho, até hoje: coligidas em virtude de autorização do exm sr conselheiro Manoel Pinto de Souza Dantas pelo bacharel José Prospero Jehovah da Silva Caroata. Rio de Janeiro: Typographia Garnier, 1884. Arquivo Histórico do Itamaraty.

PETIÇÃO de José Joaquim d'Amorim e outros, comerciantes estabelecidos no Rio de Janeiro, a José de Vasconcellos e Sousa; Rio de Janeiro, 16.01.1852; LPRJ, correspondência recebida, 1851/1853, caixa 202, maço 3, AHD-MNE. 
PURPOSES OF LAND LAW: immigration, slavery and land property in Imperial Brazil

\section{José Sacchetta Ramos Mendes}

This paper analyzes the first decades of the transition process from slavery to paid labor in Brazil (1840-1870). Two factors marked the period: the extinction of the slaves' transatlantic traffic and the need for ever larger numbers of laborers for the Brazilian coffee plantations. Among the solutions found for this impasse, the experiences that sought to use free foreign workers, such as as partnership contracts and the enganchado ones. Complaints and European farmers' revolts against mistreatments in the coffee plantations resulted in prohibition of the continuity of hiring workers to Brazil. The promulgation of the Lei Eusébio of Queirós (Eusébio de Queirós Act), that put an end to the slaves' traffic, happened two weeks before the promulgation of the Lands Act, restrictive of small farmers' access to land ownership. The obtaining of lots started happening through purchase and sale, no more for squatting and cession, as had happened since the colonial times. The measure hindered the access to small rural property and stimulated the expansion of the ownership of large tracts of land in the whole country.

KEYWORDS: work, legislation, immigration, riots, coffee, Brazilian Empire.
DESTINÉES DE LA LOI SUR LES TERRES: immigration, esclavagisme et propriété foncière à l'époque du Brésil Impérial

\author{
José Sacchetta Ramos Mendes
}

Cet article traite des premières décennies du processus de transition du régime esclavagiste au système de travail salarié au Brésil (1840-1870). Deux facteurs ont marqué cette période: l'extinction du trafic transatlantique des esclaves et le besoin chaque fois plus grand de trouver de la main d'œuvre pour la caféiculture brésilienne. Parmi les solutions trouvées pour résoudre ce problème, on peut citer les expériences d'embauche des travailleurs libres étrangers, tels que les contrats de partenariat et ceux de «dépendance». Les réclamations et les révoltes des travailleurs européens contre les mauvais traitements dans les grandes plantations de café ont entraîné l'interdiction de continuer à faire venir des travailleurs au Brésil. La promulgation de la Loi Eusébio de Queirós, qui a mis fin au trafic des esclaves, a eu lieu deux semaines avant la promulgation de la Loi sur les Terres, qui restreignait l'accès à la propriété de la terre par les agriculteurs. L'acquisition d'une parcelle de terre ne pouvait se faire que par l'achat et la vente et non plus par la possession ou la cessation comme cela se faisait à l'époque coloniale. Une telle mesure a rendu beaucoup plus difficile l'accès à la petite propriété rurale et a stimulé l'expansion des latifondiaires dans tout le pays.

MoTS-CLÉs: travail, législation, immigration, révolte, café, Empire du Brésil.

José Sacchetta Ramos Mendes - Pós-doutorando em Filosofia e Teoria do Direito da Faculdade de Direito da USP. Doutor em História Social pela Universidade de São Paulo. Pesquisador do Laboratório de Estudos sobre Etnicidade, Discriminação e Racismo (LEER/USP). Pesquisador visitante no Centro de Estudos Brasileiros da Universidade de Columbia (Nova York). Entre as suas publicações recentes estão Lei e Etnicidade no Brasil: entre a lusofobia e o favorecimento jurídico dos portugueses (São Paulo, 2009), Triângulo Imigrantista: o Caso Hessels-Carrièrre e a Re-emigração de Portugueses do Brasil para Venezuela e Antilhas (Bauru/São Paulo, 2008) e $O$ Tratado do $1^{\circ}$ Centenário. A Retórica das Duas Pátrias (Lisboa, 2006). 